\title{
Expression and significance of hypoxia-inducible factor-1 $\alpha$ and MDR1/P-glycoprotein in laryngeal carcinoma tissue and hypoxic Hep-2 cells
}

\author{
JIN XIE ${ }^{1}$, DA-WEI LI ${ }^{2}$, XIN-WEI CHEN ${ }^{1}$, FEI WANG ${ }^{1}$ and PIN DONG ${ }^{1}$ \\ ${ }^{1}$ Department of Otolaryngology-Head and Neck Surgery, Shanghai Jiao Tong University Affiliated First People's Hospital, \\ Shanghai 200080; ${ }^{2}$ Department of Otolaryngology-Head and Neck Surgery, \\ Affiliated Eye and ENT Hospital of Fudan University, Shanghai 200031, P.R. China
}

Received December 26, 2012; Accepted April 4, 2013

DOI: $10.3892 / \mathrm{ol} .2013 .1321$

\begin{abstract}
The present study aimed to evaluate the expression of hypoxia-inducible factor-1 $\alpha$ (HIF-1 $\alpha$ ) and MDR1/P-glycoprotein (P-gp) in human laryngeal squamous cell carcinoma (LSCC) tissues, and also to investigate the regulation of MDRI gene expression by HIF-1 $\alpha$ in Hep-2 cells under hypoxic conditions. The expression of HIF-1 $\alpha$ and MDR1/P-gp in human LSCC tissues was examined using immunohistochemistry. The HIF-l $\alpha$ and MDRI gene expression in the Hep-2 cells was detected using real-time quantitative reverse transcription (QRT)-PCR and western blot analysis under normoxic and hypoxic conditions. In hypoxia, HIF-1 $\alpha$ expression was inhibited by RNA interference. HIF-1 $\alpha$ and MDR1/P-gp expression was high in the LSCC tissues and was associated with the clinical stage and lymph node metastasis $(\mathrm{P}<0.05)$. HIF-1 $\alpha$ expression was positively correlated with MDR1/P-gp expression $(\mathrm{P}<0.01)$. In the Hep-2 cells, HIF-1 $\alpha$ and MDR1/P-gp expression significantly increased in response to hypoxia. The inhibition of HIF-1 $\alpha$ expression synergistically downregulated the expression of the MDRl gene in hypoxic Hep-2 cells. HIF-1 $\alpha$ expression is positively correlated with MDR1/P-gp expression in LSCC, and the two proteins may be able to serve as potential biomarkers for predicting the malignant progression and metastasis of LSCC. HIF-1 $\alpha$ may be critical for the upregulation of MDR1 gene expression induced by hypoxia in Hep-2 cells.
\end{abstract}

\section{Introduction}

It is generally known that the majority of human solid tumors contain hypoxic regions. Due to the combination of the uncon-

Correspondence to: $\mathrm{Dr}$ Pin Dong, Department of Otolaryngology-Head and Neck Surgery, Shanghai Jiao Tong University Affiliated First People's Hospital, No. 100 Haining Road, Shanghai 200080, P.R. China

E-mail: dongpin_lidawei@163.com

Key words: hypoxia, hypoxia inducible factor- $1 \alpha$, multidrug resistance, p-glycoprotein, laryngeal neoplasms trolled, rapid growth of tumor cells and the inability of the local vasculature to supply sufficient nutrients and oxygen, hypoxia has become a significant characteristic of human solid tumors. There has been a general consensus towards the theory that hypoxia plays a central role in tumor progression and resistance to chemotherapy (1).

Hypoxia is known to upregulate the expression of hypoxia-inducible factor-1 (HIF-1), which is a basic helix-loop-helix transcription factor that plays an essential role in regulating the transcription of various target genes in response to hypoxia (2). HIF-1 is a heterodimer composed of $\alpha$ and $\beta$ subunits. HIF- $1 \beta$ is considered to be an aryl hydrocarbon nuclear translocator (ARNT), whereas HIF-1 $\alpha$ has been recognized as an oxygen-regulated subunit that mediates the function of HIF-1 (3). A series of studies have previously shown that the overexpression of HIF-1 $\alpha$ was involved in the pathogenesis of tumor angiogenesis $(4,5)$, invasion $(6,7)$, metastasis (6-8) and resistance to chemotherapy $(9,10)$. Several studies have focused on whether HIF-1 $\alpha$ expression in human laryngeal carcinoma tissue is associated with tumor progression and lymph node metastasis. However, those conclusions have been inconsistent thus far $(11,12)$.

It is well known that multidrug resistance (MDR) is one of the major obstacles in the treatment of cancer using chemotherapy. In human tumors, the classic MDR phenotype is conferred by the expression of MDR1/P-glycoprotein ( $\mathrm{P}-\mathrm{gp})$, which is a member of the adenosine triphosphate (ATP)-binding cassette (ABC)-type transporter family $(10,13)$. MDR1/P-gp functions as an energy-dependent membrane efflux pump that is able to regulate the intracellular drug concentrations to determine the drug sensitivity situation of the cells. MDR1/P-gp has previously been identified to play a key role in the regulation of chemosensitivity in laryngeal cancer cells $(14,15)$. Furthermore, the downregulation of MDR1/P-gp expression has been demonstrated to be an effective way to enhance the chemosensitivity of laryngeal cancer cells to conventional chemotherapeutic agents (15). To the best of our knowledge, a series of studies have indicated that HIF-1 $\alpha$ may take part in the regulation of MDRl gene expression in multiple human tumors, including colonic (16) and hepatocellular (17) carcinoma. As yet, studies have not 
demonstrated a correlation between the HIF-1 $\alpha$ protein and $M D R 1$ gene expression in human laryngeal cancer.

The present study explored the expression and correlation of HIF- $1 \alpha$ and MDR1/P-gp in human laryngeal squamous cell carcinoma (LSCC) tissues. The study also determined whether hypoxia exhibited an effect on the regulation of $M D R 1$ gene expression in Hep-2 cells, and the role of HIF-1 $\alpha$ in the transcriptional regulation of $M D R l$ gene expression in hypoxic Hep-2 cells.

\section{Materials and methods}

Patients and tissue samples. Paraffin-embedded surgical tissue specimens were obtained from the pathological files of 86 patients with LSCC that had been admitted to the Shanghai Jiao Tong University Affiliated First People's Hospital (Shanghai, China). All the patients involved in the study were treated between January 1997 and December 2008, and underwent surgery for LSCC in the Department of Otolaryngology-Head and Neck Surgery. A total of 81 male and 5 female patients, with ages ranging between 37 and 84 years (median age, 51 years) were selected. None of the patients had undergone treatment prior to surgery. All patients had a histopathological diagnosis of squamous cell carcinoma, as determined by pathologists. The clinicopathological data are shown in Table I. According to the anatomical site of the primary tumor, 18 cases of supraglottic laryngeal carcinoma, 66 cases of glottic carcinoma and two cases of subglottic carcinoma were diagnosed. The disease stage was determined according to the 2002 TNM classification of the International Union Against Cancer (UICC, Geneva, Switzerland) (18). The histological grade of the tumor was determined according to the degree of differentiation (Broders' classification). Approval for the study was obtained from the Ethics Committee of The Shanghai Jiao Tong University Affiliated First People's Hospital and informed consent was obtained from all participants.

Immunohistochemistry. The paraffin-embedded tissues were cut into 5- $\mu \mathrm{m}$ sections, deparaffinized in xylene and dehydrated through a graded series of ethanol solutions. The antigen retrieval was performed by heating the sections for $18 \mathrm{~min}$ in a microwave oven with a citrate buffer $(10 \mathrm{mmol} / \mathrm{l}$, $\mathrm{pH}$ 6.0). The slides were washed in phosphate-buffered saline (PBS) and the endogenous peroxidase activity was halted (3\% hydrogen peroxide in methanol for $10 \mathrm{~min}$ ), followed by incubation in $10 \%$ normal goat serum for $30 \mathrm{~min}$ to minimize undesirable non-specific staining. The tissue sections were then incubated with the following primary antibodiesovernight at $4^{\circ} \mathrm{C}$ : mouse anti-HIF-1 $\alpha$ monoclonal antibody (Millipore Corporation, Billerica, MA, USA) at 1:100 dilution and mouse anti-MDR1/P-gp monoclonal antibody (ab3366; Abcam, Cambridge, UK) at 1:40 dilution. Immunodetection was performed by a two-step immunohistochemistry procedure using the Envision System, with diaminobenzidine chromogen as a substrate (DAKO, Carpinteria, CA, USA) and according to the manufacturer's instructions. Finally, the nuclei were counterstained using hematoxylin solution and the negative controls were incubated with PBS in place of the primary antibody.
Evaluation of staining. The results of the immunoreactivity procedure were evaluated independently by two pathologists who had no prior knowledge of the clinicopathological patient data. The immunohistochemical assessment of the expression of HIF-1 $\alpha$ (19) and MDR1/P-gp (20) in the human LSCC tissues was performed using a semi-quantitative scoring system, as described in previous studies. HIF-1 $\alpha$ immunostaining was evaluated as a percentage of the nuclear positivity by counting the positive tumor nuclei, regardless of cytoplasmic staining. A positive classification was awarded if the percentage of positive tumor cells was $>10 \%$. All the other cases were considered to be in the negative category. The MDR1/P-gp immunoreactivity specimens that scored 0 were defined as in the negative category and all others were placed into the positive category.

Cell line and culture. The Hep-2 human laryngeal carcinoma cell line was obtained from the American Type Culture Collection (ATCC, Manassas, VA, USA) and was cultured in high-glucose Dulbecco's modified Eagle's medium (DMEM; Gibco Corporation, Carlsbad, CA, USA) with $10 \%$ fetal bovine serum (Hyclone, Logan, UT, USA) and antibiotics (100 IU/ml penicillin and $100 \mathrm{IU} / \mathrm{ml}$ streptomycin). The normoxic control cells were incubated in a humidified atmosphere consisting of $95 \%$ air and $5 \% \mathrm{CO}_{2}$ at $37^{\circ} \mathrm{C}$. For the hypoxic conditions, the well-developed Hep-2 cells were cultured for $24 \mathrm{~h}$ in a modulator incubator chamber at $37^{\circ} \mathrm{C}$, with $94 \% \mathrm{~N}_{2}, 1 \% \mathrm{O}_{2}$ and $5 \% \mathrm{CO}_{2}$.

Inhibition of HIF-1 $\alpha$ expression in Hep-2 cells by RNA interference. A double stranded siRNA oligonucleotide targeting the HIF-1 $\alpha$ gene (sense, 5-CUGAUGACCAGCAACUUGAdTdT-3 and anti-sense, 5-UCAAGUUGCUGGUCAUCAGdTdT-3) was synthesized according to the human HIF-1 $\alpha$ complementary deoxyribonucleic acid (cDNA) sequence in the gene bank (NM001530; Shanghai Genepharma Co.,Ltd., Shanghai, China), which was previously identified (21). A non-specific control siRNA (forward, 5-AGUUCAACGACCAGUAGUCdTdT-3 and reverse, 5-GACUACUGGUCGUUGAdTdT-3) was designed by a basic alignment search tool (BLAST) search (National Center for Biotechnology Information database, Bethesda, MD, USA) and synthesized by the Genepharma Company. This was not homologous to any human transcripts in the records. The Hep- 2 cells were incubated in an antibiotic-free medium for $24 \mathrm{~h}$ prior to transfection with siRNA (100 nM) using Lipofectamine 2000 (Invitrogen, Carlsbad, CA, USA) according to the manufacturer's instructions. The cells were harvested and examined following $24 \mathrm{~h}$ of transfection.

Real-time quantitative reverse transcription ( $Q R T)$ - $P C R$ for $H I F-1 \alpha$ and MDR1. The total RNA was extracted by Trizol reagent (Invitrogen) according to the manufacturer's instructions. The RT reaction was performed using the ExScriptRT reagent kit (Takara, Shiga, Japan) in a final reaction mixture consisting of $1 \mu \mathrm{g}$ total RNA, $4 \mu \mathrm{l}$ XX ExScript buffer, $1 \mu \mathrm{l}$ OligodT primer, $1 \mu \mathrm{l}$ deoxynucleotide triphosphate (DNTP) mixture, $0.5 \mu 1$ RNase inhibitor, $0.5 \mu 1$ ExScript RTase and RNase-free water to $20 \mu \mathrm{l}$ liquid. The RT reaction comprised of an initial step at $42^{\circ} \mathrm{C}$ for $15 \mathrm{~min}$ and was terminated by heating at $95^{\circ} \mathrm{C}$ for $2 \mathrm{~min}$. The QRT-PCR was then executed using the ABI Prism 7900 real-time PCR system with SYBR-Green 1 
Table I. Correlation between clinicopathological features and HIF-1 $\alpha$ and MDR1/P-gp expression in 86 cases of human laryngeal carcinoma.

\begin{tabular}{|c|c|c|c|c|c|c|c|c|c|}
\hline \multirow{2}{*}{$\begin{array}{l}\text { Clinicopathological } \\
\text { parameter }\end{array}$} & \multirow[b]{2}{*}{$\mathrm{N}$} & \multicolumn{2}{|c|}{ HIF-1 $1 \alpha, \mathrm{n}$} & \multirow[b]{2}{*}{$\chi^{2}$} & \multirow[b]{2}{*}{ P-value } & \multicolumn{2}{|c|}{ MDR1/P-gp, n } & \multirow[b]{2}{*}{$\chi^{2}$} & \multirow[b]{2}{*}{ P-value } \\
\hline & & Positive & Negative & & & Positive & Negative & & \\
\hline Age (years) & & & & 1.061 & 0.303 & & & 2.237 & 0.135 \\
\hline$<60$ & 55 & 38 & 17 & & & 25 & 30 & & \\
\hline$\geq 60$ & 31 & 18 & 13 & & & 9 & 22 & & \\
\hline Primary location & & & & 0.665 & 0.717 & & & 3.518 & 0.172 \\
\hline Supraglottic & 18 & 13 & 5 & & & 8 & 10 & & \\
\hline Glottic & 66 & 42 & 24 & & & 24 & 42 & & \\
\hline Subglottic & 2 & 1 & 1 & & & 2 & 0 & & \\
\hline Histological grade & & & & 0.066 & 0.968 & & & 6.658 & 0.038 \\
\hline I & 29 & 19 & 10 & & & 6 & 23 & & \\
\hline II & 44 & 28 & 16 & & & 21 & 23 & & \\
\hline III & 13 & 8 & 5 & & & 7 & 6 & & \\
\hline Clinical stage & & & & 5.346 & 0.021 & & & 5.978 & 0.024 \\
\hline I-II & 63 & 36 & 27 & & & 20 & 43 & & \\
\hline III-IV & 23 & 20 & 3 & & & 14 & 9 & & \\
\hline Lymph node status & & & & 4.417 & 0.036 & & & 4.433 & 0.035 \\
\hline Positive & 18 & 16 & 2 & & & 11 & 7 & & \\
\hline Negative & 68 & 40 & 28 & & & 23 & 45 & & \\
\hline
\end{tabular}

HIF-1 $\alpha$, hypoxia-inducible factor-1 $\alpha$; MDR1/P-gp, MDR1/P-glycoprotein.

(Invitrogen). The primers were as follows: HIF-l $\alpha$ forward, 5'-AACATAAAGTCTGCAACATGGAAG-3' and reverse, 5'-AACATAA AGTCTGCAACATGGAAG-3'; MDRI forward, 5'-CTTCAGGGTTTCACATTTGGC-3' and reverse, 5'-GGTAGTCAATGCTCCAGTGG-'3; GAPDH (internal control) forward, 5'-CATCTTCCAGGAGCGAGA-'3 and reverse, 5'-TGTTGTCATACTTCTCAT-3'. The PCR amplification was carried out in a $20 \mu \mathrm{l}$ final reaction mixture containing a diluted cDNA solution, $10 \mu \mathrm{M}$ of each primer and $10 \mu 1$ SYBR-Green PCR Master Mix. The thermal cycling conditions were presented as the following: one cycle at $95^{\circ} \mathrm{C}$ for $10 \mathrm{~min}, 40$ cycles at $95^{\circ} \mathrm{C}$ for $15 \mathrm{sec}$ and then one cycle at $60^{\circ} \mathrm{C}$ for $60 \mathrm{sec}$. The data were analyzed using the $2^{\Delta \triangle C T}$ method as previously described (22).

Western blot analysis for HIF-1 $\alpha$ and MDRI/P-gp. The Hep-2 cells were harvested and lysed with a cold radio-immunoprecipitation assay (RIPA) protein lysis buffer. Following sonication and incubation on ice for $30 \mathrm{~min}$, the lysates were transferred into Eppendorf tubes, which were centrifugated at $12,000 \mathrm{x} \mathrm{g}$ for $40 \mathrm{~min}$ at $4^{\circ} \mathrm{C}$. The protein concentration of the supernatant was determined by the Bradford method. The samples were then boiled at $95^{\circ} \mathrm{C}$ for $5 \mathrm{~min}$ and loaded onto SDS-PAGE (5\% stacking gel and $8 \%$ separating gel for HIF-1 $\alpha$ and MDR1/P-gp), followed by a separation at $80 \mathrm{~V}$ for $\sim 2 \mathrm{~h}$, prior to being transferred onto a polyvinylidene difluoride (PVDF) membrane (Millipore). The membrane was blocked using $4 \%$ skimmed milk for $1.5 \mathrm{~h}$ at room temperature. Following this, the samples were incubated with primary antibodies overnight at $4^{\circ} \mathrm{C}$ (HIF-1 $\alpha$ 1:100, mouse anti-human; MDR1/P-pg, 1:200, mouse anti-human; and $\beta$-actin, 1:1,000, rabbit anti-human). Horseradish peroxidase-conjugated secondary antibodies against rabbit or mouse IgG (BossBio, Beijing, China) were used to incubate the membrane for $1 \mathrm{~h}$ at room temperature. Finally, the protein gel bands were detected by enhanced chemiluminescence (ECL; Amersham Pharma Biotech, Amersham, UK), according to the manufacturer's instructions.

Statistical analysis. Statistical analysis was performed using SPSS 13.0 statistical software (Chicago, IL, USA). The categorical variables were assessed by $\chi^{2}$ or Fisher's exact tests. Comparisons of the quantitative variables were analyzed by the Student's t-test or a one-way ANOVA. The Spearman's rank correlation test was used to determine the correlation between HIF-1 $\alpha$ and MDR1/P-pg expression. For all tests, $\mathrm{P}<0.05$ was considered to indicate a statistically significant difference.

\section{Results}

Expression of HIF-1 $\alpha$ and MDR1/P-gp in human LSCC tissue. Immunostaining for HIF-1 $\alpha$ was observed in $56(65.1 \%)$ of the 86 laryngeal cancer tissues. The staining was not only localized in the cell nuclei, but was also observed in the cytoplasm of the tumor cells (Fig. 1A). However, HIF-1 $\alpha$ nuclear staining was negatively expressed in the 32 normal laryngeal mucosa tissues $(\mathrm{P}<0.05$; Fig. 1B). MDR1/P-gp 

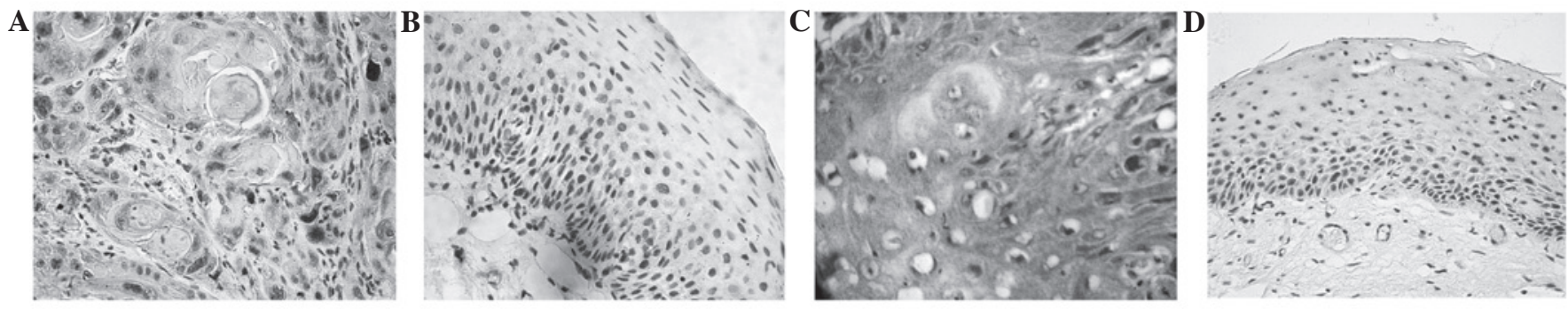

Figure 1. Immunohistochemical staining of HIF-1 $\alpha$ and MDR1/P-gp in human laryngeal carcinoma and normal laryngeal epithelium. (A) HIF-1 $\alpha$ was expressed in the nuclei and cytoplasm of the tumor cells (x400). (B) HIF-1 $\alpha$ expression was negative in the normal laryngeal epithelium (x400). (C) MDR1/P-gp was mainly localized in the cytoplasm and cytomembrane of the tumor cells (x400). (D) MDR1/P-gp expression was negative in the normal laryngeal epithelium (x400). HIF-1 $\alpha$, hypoxia-inducible factor-1 $\alpha$; MDR1/P-gp, MDR1/P-glycoprotein.

A

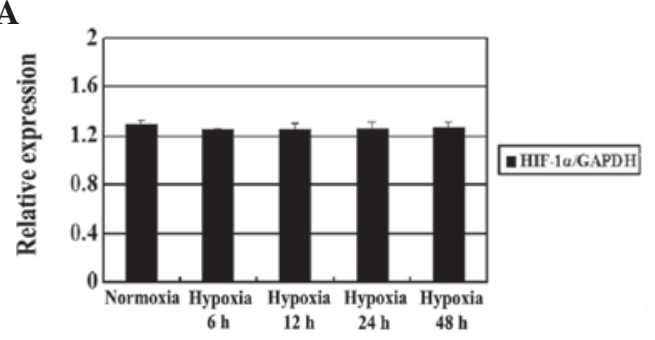

C

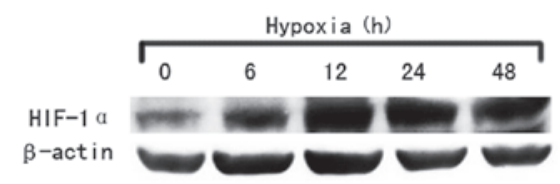

$\mathbf{E}$

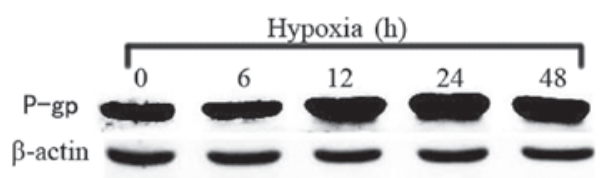

B

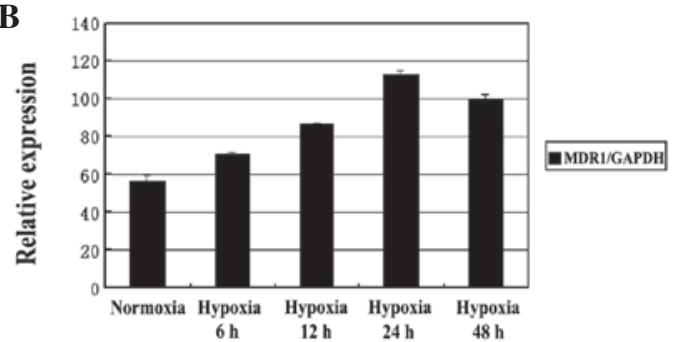

D

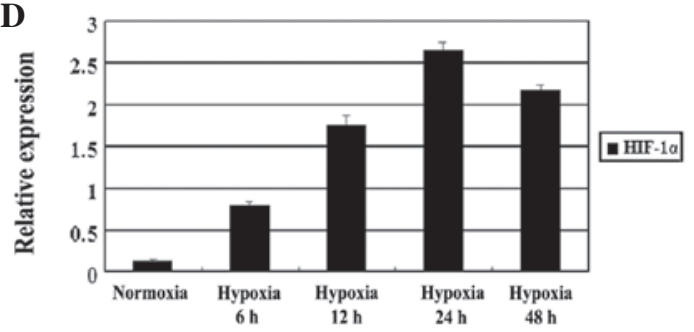

F

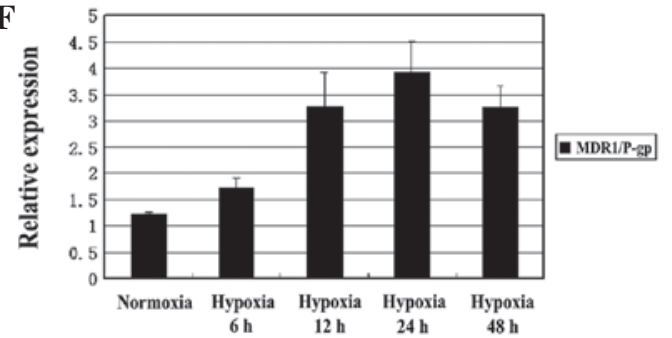

Figure 2. Expression of HIF-1 $\alpha$ and the MDR1 gene in Hep-2 cells under normoxic and hypoxic conditions. Hep-2 cells were incubated in $10 \%$ fetal bovine serum medium under normoxia or hypoxia at the indicated times. The relative values of (A) HIF-1 $\alpha$ and (B) MDRI mRNA to GAPDH mRNA were detected by QRT-PCR. The expression of (C) HIF-1 $\alpha$ and (D) MDR1/P-gp in the Hep-2 cells was determined by western blot analysis. The graphs represent the gray values (relative expression of the protein) of (E) HIF-1 $\alpha$ and (F) MDR1/P-gp. N, normoxia; H, hypoxia; HIF-1 $\alpha$, hypoxia-inducible factor-1 $\alpha$; MDR1/P-gp, MDR1/P-glycoprotein; QRT-PCR, real-time quantitative reverse transcription PCR.

immunostaining was identified in 34 (39.5\%) of the 86 LSCC tissue samples and was predominantly expressed in the cytoplasm and cytomembrane of the LSCC cells (Fig. 1C). In contrast, MDR 1/P-gp expression was only observed in 3.1\% $(1 / 32)$ of the normal laryngeal mucosa samples (Fig. 1D), which was significantly lower than in the laryngeal cancer samples $(\mathrm{P}<0.05)$. Among the LSCC samples, HIF-1 $\alpha$ expression was closely associated with the clinical stage and level of lymphatic invasion of the tumor cells $(\mathrm{P}<0.05)$. However, no differences were noted in the HIF-1 $\alpha$ expression following changes in the age of the patients or the histological grade or primary location of the tumors (P>0.05; Table I). MDR1/P-pg expression in the human laryngeal tissue was not correlated with age or primary site $(P>0.05)$, but was correlated with the clinical stage, differentiation grade and lymph node metastasis $(\mathrm{P}<0.05$; Table I). Furthermore, a positive linear correlation was observed between HIF-1 $\alpha$ and MDR1/P-pg expression in the LSCC tissues ( $\mathrm{r}=0.442, \mathrm{P}<0.01$; Table II).

Hypoxia induces HIF-1 $\alpha$ and MDRI expression. When the Hep-2 cells were exposed to hypoxia for $6,12,24$ or $48 \mathrm{~h}$, the expression of HIF-l $\alpha$ and MDRl was detected by QRT-PCR 
Table II. Correlation between HIF-1 $\alpha$ and MDR1/P-gp expression in human laryngeal carcinoma tissue.

\begin{tabular}{lccc}
\hline & \multicolumn{3}{c}{ HIF-1 $\alpha$ (No. of cases) } \\
\cline { 2 - 4 } $\begin{array}{l}\text { MDR1/P-gp } \\
\text { No. of cases) }\end{array}$ & Positive & Negative & Total \\
\hline Positive & 31 & 25 & 56 \\
Negative & 3 & 27 & 30 \\
Total & 34 & 52 & 86 \\
\hline
\end{tabular}

$\mathrm{R}=0.442 ; \mathrm{P}<0.01, \mathrm{HIF}-1 \alpha$ vs. MDR1/P-gp expression. HIF-1 $\alpha$, hypoxia-inducible factor-1 $\alpha$; MDR1/P-gp, MDR1/P-glycoprotein.
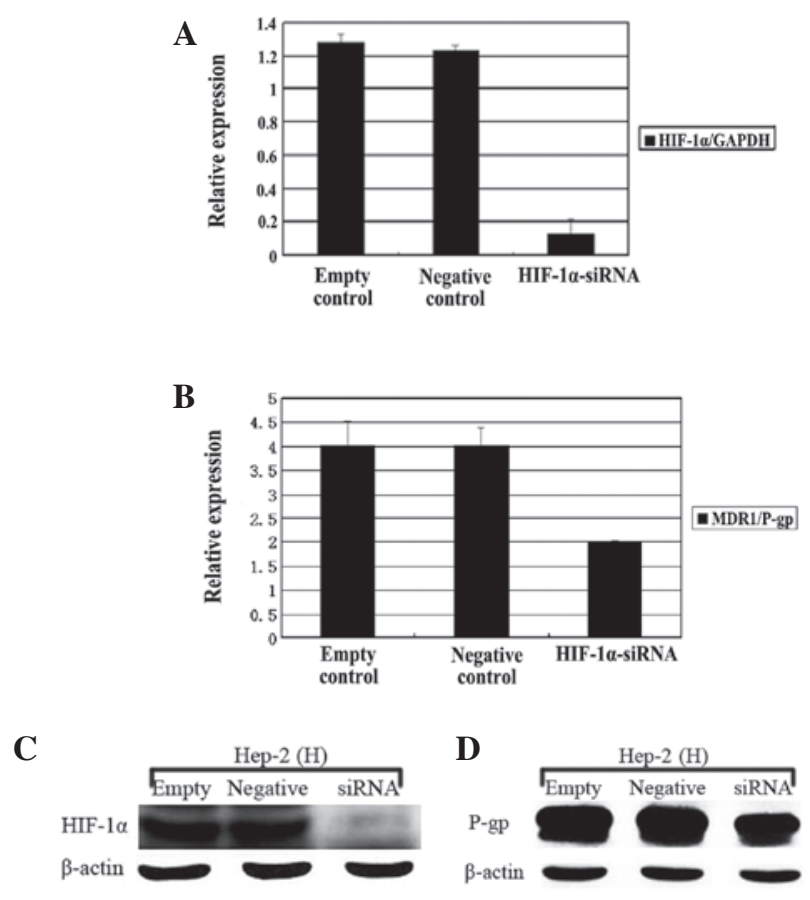

Figure 3. Downregulated HIF-1 $\alpha$ expression repressing the expression of the MDRl gene in hypoxic Hep-2 cells. Hep-2 cells were transfected with either a vector containing a $H I F-1 \alpha$ scrambled or a vector containing a $H I F-1 \alpha$ targeting sequence (HIF- $1 \alpha$-siRNA) and then incubated in hypoxic conditions for $24 \mathrm{~h}$. Total RNA was then isolated and analyzed by QRT-PCR for (A) HIF-1 $\alpha$ and (B) MDRI mRNA expression. Cell lysates were prepared and detected by western blot analysis for (C) HIF-1 $\alpha$ and (D) MDR1/P-gp expression. HIF-1 $\alpha$, hypoxia-inducible factor-1 $\alpha$; MDR1/P-gp, MDR1/P-glycoprotein; QRT-PCR, real-time quantitative reverse transcription PCR.

and western blot analysis. As shown in Figure 2, the MDR1 mRNA expression was gradually elevated as the hypoxia was prolonged when compared with the normoxic group. The maximum level of MDR $1 \mathrm{mRNA}$ was observed at $24 \mathrm{~h}$ $(\mathrm{P}<0.01)$. However, no significant differences were observed in the expression levels of the HIF-1 $\alpha$ mRNA $(\mathrm{P}>0.05)$. Western blot analysis revealed that the hypoxia caused a time-dependent increase in the expression of the HIF-1 $\alpha$ and MDR1/P-gp proteins, reaching a climax at $24 \mathrm{~h}$ under hypoxic conditions $(\mathrm{P}<0.05$; Fig. 3$)$.
Role of HIF-1 $\alpha$ in MDRl gene induction. In order to explore the role of HIF-1 $\alpha$ in hypoxia-induced $M D R 1$ gene expression, the Hep-2 cells were transfected with a double stranded siRNA oligonucleotide targeting the $H I F-1 \alpha$ gene or non-specific control siRNA for $24 \mathrm{~h}$ prior to incubation under normoxic or hypoxic conditions. As shown in Figure 3A and B, in comparison with the negative or untreated controls, the mRNA and protein expression of HIF-1 $\alpha$ in the hypoxic Hep- 2 cells was markedly reduced following transfection by the siRNA targeting the $H I F-1 \alpha$ gene (HIF- $1 \alpha-$-siRNA; P<0.01). Similarly, Fig. 3C and D showed that the HIF-1 $\alpha$-siRNA also resulted in the significant downregulation of the MDR 1 mRNA and protein in the Hep-2 cells that were cultured under hypoxic conditions $(\mathrm{P}<0.05)$.

\section{Discussion}

LSCC is one of the most common solid malignancies of the head and neck region. At present, the molecular mechanisms that contribute to the invasion, metastasis and resistance to chemotherapy by the LSCC cells remain unclear. Thus, it is of vital importance that potential biomarkers are identified that reflect the biological characteristics of neoplasms, in addition to the prognosis of patients. HIF-1 $\alpha$ has previously been demonstrated to perform a vital role in modulating the biological characteristics of tumor cells, including angiogenesis, unlimited growth and resistance to chemotherapy (21). Currently, there is no shortage of controversy with regard to a correlation between HIF-1 $\alpha$ expression and the tumor progression and lymph node metastasis of LSCC. Wu et al (11) indicated that HIF-1 $\alpha$ expression in laryngeal cancer tissues was closely associated with tumor stage and lymph node metastasis. However, Cabanillas et al (12) observed that HIF-1 $\alpha$ expression in LSCC cells correlated with the T-classification of tumors, but was not associated with any other clinicopathological variables. The data from the present study were consistent with the results from the study by $\mathrm{Wu}$ et al, confirming that the expression of HIF-1 $\alpha$ in human LSCC tissues was significantly associated with the tumor stage and lymph node metastasis. The assessment of HIF-1 $\alpha$ expression in the LSCC tissues may be conducive to predicting the status of tumor progression and metastasis.

It is well known that MDR1/P-gp is considered a bifunctional regulator of multidrug resistance that exists in a wide variety of tumors, including LSCC $(14,15)$. Additionally, several studies have revealed that MDR1/P-pg may have an effect on promoting the invasion of human cancer cells $(23,24)$. To date, substantial attention has been focused on the correlation between MDR1/P-gp expression and the clinicopathological features in human malignancies. Certain studies demonstrated that MDR1/P-gp expression in human cancer is associated with histological differentiation (25), tumor stages (16) and lymphatic invasion (16). However, Sagol et al (26) showed that no significant correlation was evident between MDR1/P-gp expression and the clinicopathological variables in pancreatic carcinoma. To further strengthen the evidence linking MDR1/ P-gp expression with the clinical status of LSCC, the present study investigated the expression level of MDR1/P-gp in 86 cases of human LSCC tissue. Accordingly, the data revealed that the MDR1/P-gp expression in the laryngeal cancer tissues was closely correlated with tumor stage, lymph node metas- 
tasis and histological grade, suggesting that MDR1/P-gp may have an effect on the tumor progression and cell differentiation of LSCC. At present, the in vivo study of the correlation between HIF-1 $\alpha$ and MDR1/P-gp expression in human cancer cells remains limited. The present data provided evidence of a positive correlation between HIF-1 $\alpha$ and MDR1/P-gp expression in human LSCC tissues.

It is commonly accepted that hypoxia is able to induce a change in the physiology and biochemistry of tumor cells by regulating the expression of multiple genes in order to adapt to a hypoxic microenvironment. Previous studies have confirmed that hypoxia may take part in the regulation of tumor cell chemoresistance $(27,28)$. In particular, a number of studies have revealed that hypoxia may contribute to chemoresistance by enhancing the expression of the MDR1 gene in tumor cells $(27,28)$. However, Song et al (29) indicated that the regulation of $M D R 1$ gene expression may not be involved in hypoxia-induced chemoresistance in human non-small cell lung cancer. The present data showed that hypoxia had a significant effect on mediating the upregulation of $M D R 1$ gene expression in the laryngeal carcinoma Hep- 2 cells. The differences between the previously cited studies may have been due to the intrinsic distinctions in the molecular mechanisms for the regulation of chemoresistance in the various types of neoplastic cells.

$\mathrm{HIF}-1 \alpha$ is a major transcriptional regulator of multiple target genes that are implicated in cellular adaptive responses to hypoxia (21). The present study confirmed that the HIF-1 $\alpha$ protein was minimally expressed in the Hep-2 cells under normoxic conditions, whereas its expression was markedly increased in the hypoxic Hep-2 cells, further supporting the theory that HIF-1 $\alpha$ is an oxygen-regulated protein. To the best of our knowledge, multiple in vitro studies have demonstrated that HIF-1 $\alpha$ may play a key role in the induction of $M D R l$ gene expression in tumor cells under hypoxic conditions $(30,31)$. Unfortunately, the role of HIF-1 $\alpha$ in the regulation of $M D R 1$ gene expression in laryngeal cancer cells under hypoxic conditions has not yet been clarified. In the present study, a significant reduction of MDRl gene expression in the hypoxic Hep-2 cells was observed following the inhibition of HIF-1 $\alpha$ expression using transfected siRNA molecules, suggesting that HIF-1 $\alpha$ may play an integral role in the regulation of MDRl gene expression in hypoxic LSCC cells. To date, the molecular mechanisms of HIF-1 $\alpha$-regulated MDR 1 gene expression in laryngeal cancer cells remain undefined and require further investigation.

The present study has shown that HIF-1 $\alpha$ expression is significantly correlated with MDR1/P-gp expression in LSCC, and that the two proteins may serve as potential biomarkers for predicting the malignant progression and metastasis of human LSCC. Moreover, the data demonstrate that hypoxia may enhance the expression of the MDRl gene in Hep-2 cells. As a key nuclear transcription factor, HIF-1 $\alpha$ exerts a positive regulatory effect on $M D R l$ gene expression in response to hypoxia in laryngeal cancer Hep-2 cells. Thus, targeting the HIF-1 $\alpha / \mathrm{MDR} 1 / \mathrm{P}$-gp signaling pathway may be a potential therapeutic strategy for treating LSCC.

\section{Acknowledgements}

The authors would like to thank Dr Jia-wei Chen, Department of Pathology, Shanghai Jiao Tong University
Affiliated First People's Hospital, for the database of clinical indices. The authors also thank Professor Jin-ke Cheng and Yan-qiong Zou, Morphology and Cell Chemistry Laboratory of Shanghai Jiao Tong University School of Medicine, for their technical assistance. This study was supported by the Shanghai Science and Technology Development Fund, China (no. 09411951000).

\section{References}

1. Wilson WR and Hay MP: Targeting hypoxia in cancer therapy. Nat Rev Cancer 11: 393-410, 2011.

2. Li Y and Ye D: Cancer-therapy by targeting hypoxia-inducible factor-1. Curr Cancer Drug Targets 10: 782-796, 2010.

3. O'Donnell JL, Joyce MR, Shannon AM, Harmey J, Geraghty J and Bouchier-Hayes D: Oncological implications of hypoxia inducible factor-1alpha (HIF-1alpha) expression. Cancer Treat Rev 32: 407-416, 2006.

4. Liu LZ, Li C, Chen Q, et al: MiR-21 induced angiogenesis through AKT and ERK activation and HIF-1 $\alpha$ expression. PLoS One 6: e19139, 2011

5. Park SY, Jang WJ, Yi EY, Jang JY, Jung Y, Jeong JW and Kim YJ: Melatonin suppresses tumor angiogenesis by inhibiting HIF-1alpha stabilization under hypoxia. J Pineal Res 48: 178-184, 2010.

6. Jing SW, Wang YD, Kuroda M, et al: HIF-1 $\alpha$ contributes to hypoxia-induced invasion and metastasis of esophageal carcinoma via inhibiting E-cadherin and promoting MMP-2 expression. Acta Med Okayama 66: 399-407, 2012.

7. Song G, Ouyang G, Mao Y, Ming Y, Bao S and Hu T: Osteopontin promotes gastric cancer metastasis by augmenting cell survival and invasion through Akt-mediated HIF-1alpha upregulation and MMP9 activation. J Cell Mol Med 13: 1706-1718, 2009.

8. Huang L, Zhang Z, Zhang S, et al: Inhibitory action of Celastrol on hypoxia-mediated angiogenesis and metastasis via the HIF-1 $\alpha$ pathway. Int J Mol Med 27: 407-415, 2011.

9. Rho JK, Choi YJ, Lee JK, et al: Gefitinib circumvents hypoxia-induced drug resistance by the modulation of HIF-1alpha. Oncol Rep 21: 801-807, 2009.

10. Huang C, Xu D, Xia Q, Wang P, Rong C and Su Y: Reversal of P-glycoprotein-mediated multidrug resistance of human hepatic cancer cells by Astragaloside II. J Pharm Pharmacol 64: 1741-1750, 2012.

11. Wu XH, Lu YF, Hu XD, Mao JY, Ji XX, Yao HT and Zhou SH: Expression of hypoxia inducible factor- $1 \alpha$ and its significance in laryngeal carcinoma. J Int Med Res 38: 2040-2046, 2010.

12. Cabanillas R, Rodrigo JP, Secades P, Astudillo A, Nieto CS and Chiara MD: The relation between hypoxia-inducible factor (HIF)-1alpha expression with p53 expression and outcome in surgically treated supraglottic laryngeal cancer. J Surg Oncol 99: 373-378, 2009.

13. Hao YX, He ZW, Zhu JH, Shen Q, Sun JZ, Du N and Xiao WH: Reversal of multidrug resistance in renal cell carcinoma by short hairpin RNA targeting MDR1 gene. Chin Med J (Engl) 125: 2741-2745, 2012.

14. Li L, Jiang AC, Dong P, Wan Y and Yu ZW: The characteristics of Hep-2 cell with multiple drug resistance induced by Taxol. Otolaryngol Head Neck Surg 137: 659-664, 2007.

15. Zhigang H, Qi Z, Jugao F, et al: Reverse multidrug resistance in laryngeal cancer cells by knockdown MDR1 gene expression. J Otolaryngol Head Neck Surg 38: 440-448, 2009.

16. Ding Z, Yang L, Xie X, et al: Expression and significance of hypoxia-inducible factor-1 alpha and MDR1/P-glycoprotein in human colon carcinoma tissue and cells. J Cancer Res Clin Oncol 136: 1697-1707, 2010.

17. Zhu H, Luo SF, Wang J, et al: Effect of environmental factors on chemoresistance of HepG2 cells by regulating hypoxia-inducible factor-1 $\alpha$. Chin Med J (Engl) 125: 1095-1103, 2012.

18. Psychogios G, Waldfahrer F, Bozzato A and Iro H: Evaluation of the revised TNM classification in advanced laryngeal cancer. Eur Arch Otorhinolaryngol 267: 117-121, 2010.

19. Batmunkh E, Shimada M, Morine Y, et al: Expression of hypoxia-inducible factor-1 alpha (HIF-1alpha) in patients with the gallbladder carcinoma. Int J Clin Oncol 15: 59-64, 2010.

20. Ng IO, Liu CL, Fan ST and Ng M: Expression of P-glycoprotein in hepatocellular carcinoma. A determinant of chemotherapy response. Am J Clin Pathol 113: 355-363, 2000. 
21. Sowter HM, Raval RR, Moore JW, Ratcliffe PJ and Harris AL: Predominant role of hypoxia-inducible transcription factor (Hif)-1alpha versus Hif-2alpha in regulation of the transcriptional response to hypoxia. Cancer Res 63: 6130-6134, 2003.

22. Livak KJ and Schmittgen TD: Analysis of relative gene expression data using real-time quantitative PCR and the 2[-Delta Delta C(T)] Method. Methods 25: 402-408, 2001.

23. Li L, Jiang AC, Dong P, Wang H, Xu W and Xu C: MDR1/P-gp and VEGF synergistically enhance the invasion of Hep-2 cells with multidrug resistance induced by taxol. Ann Surg Oncol 16 : 1421-1428, 2009.

24. Miletti-González KE, Chen S, Muthukumaran N, et al: The CD44 receptor interacts with P-glycoprotein to promote cell migration and invasion in cancer. Cancer Res 65: 6660-6667, 2005

25. Tokunaga Y, Hosogi H, Hoppou T, Nakagami M, Tokuka A and Ohsumi K: Effects of MDR1/P-glycoprotein expression on prognosis in advanced colorectal cancer after surgery. Oncol Rep 8: 815-819, 2001

26. Sagol O, Yavuzsen T, Oztop I, et al: The effect of apoptotic activity, survivin, $\mathrm{Ki}-67$, and P-glycoprotein expression on prognosis in pancreatic carcinoma. Pancreas 30: 343-348, 2005.
27. Wartenberg M, Ling FC, Müschen M, et al: Regulation of the multidrug resistance transporter P-glycoprotein in multicellular tumor spheroids by hypoxia-inducible factor (HIF-1) and reactive oxygen species. FASEB J 17: 503-505, 2003.

28. Xia S, Yu SY, Yuan XL and Xu SP: Effects of hypoxia on expression of P-glycoprotein and multidrug resistance protein in human lung adenocarcinoma A549 cell line. Zhonghua Yi Xue Za Zhi 84: 663-666, 2004 (In Chinese).

29. Song X, Liu X, Chi W, Liu Y, Wei L, Wang X and Yu J: Hypoxia-induced resistance to cisplatin and doxorubicin in non-small cell lung cancer is inhibited by silencing of HIF-1alpha gene. Cancer Chemother Pharmacol 58: 776-784, 2006.

30. Liu L, Ning X, Sun L, et al: Hypoxia-inducible factor-1 alpha contributes to hypoxia-induced chemoresistance in gastric cancer. Cancer Sci 99: 121-128, 2008.

31. Min L, Chen Q, He S, Liu S and Ma Y: Hypoxia-induced increases in A549/CDDP cell drug resistance are reversed by RNA interference of HIF-1 $\alpha$ expression. Mol Med Report 5: 228-232, 2012. 